\title{
Retraction of: Med Acupunct. 2016;28(6):339-348; DOI: 10.1089/acu.2016.1172
}

Medical Acupuncture is officially retracting the article entitled "Effects of Acupuncture on 1-Chloro-2,4Dinitrochlorobenzene-Induced Allergic Contact Dermatitis in Mice'” by Zhang et al. [Med Acupunct. 2016;28(6):339-348; DOI: 10.1089/acu.2016.1172].

After publication of the article, the authors contacted the Editor requesting its withdrawal due to incorrect data found in Figures 6 and 7.

Medical Acupuncture is committed to the highest standards of peer review and to the integrity of scientific publishing and the community it serves and, therefore, officially retracts this article from the literature. 